\title{
Overview of Energy Savings and Efficiency Strategies at the University of Jordan Hospital
}

\author{
K. Hassouneh ${ }^{a, *}$, S. Suleiman ${ }^{a}$, and A. Al-Salaymeh ${ }^{b}$ \\ ${ }^{a}$ Architecture Engineering Department, School of Engineering, University of Jordan, Amman, 11942, Jordan \\ ${ }^{b}$ Mechanical Engineering Department, School of Engineering, University of Jordan, Amman 11942 Jordan
}

\begin{abstract}
The main objective of this study is to conduct an Energy Auditing of The University of Jordan Hospital. This hospital is quite known, as one of Jordan's leading hospitals in human resources and equipment; however, the energy consumption of the hospital over the past few years has proven to be highly expensive. This makes the saving on costs of energy consumption a high priority that cannot be ignored. Energy audit covers the three main sections of the hospital: the Emergency Building, the Clinics Building and the Main Hospital Building. The consumption of energy, which costs the hospital a total of $2,778,426 \mathrm{JD} / \mathrm{yr}$., can be categorized into three main parts, the lighting system, the diesel fuel consumption, and the consumption of water. After analyzing the energy invoices, and visiting the site for inspection, a list of recommended solutions that are applicable to cut down the total energy bill were derived. The implementation of renewable energy was suggested and studied of which a solar water heating system was proposed. A study on photovoltaic cells technology was performed for a sample of guest's rooms, the number of panels needed was found. After that, a feasibility study was conducted. The initial costs, annual savings and payback periods of the suggested system were estimated by the current market prices. It is found that the energy auditing and the solutions would be very beneficial as it will save a total annual value of 346,853 JDs (12.5\% of the current energy bill).
\end{abstract}

Keywords: Energy saving, energy audit, payback period

\section{Introduction}

Energy is one of the major inputs for the economic development of any country. In the case of the developing countries, the energy sector assumes a critical importance in view of the everincreasing energy needs requiring huge investments to meet them [1]. Jordan imports most of its energy needs. The energy issue has posed a difficult challenge for Jordan. Its lack of conventional commercial energy resources places a burden on the national economy due to the relatively high cost of imported oil and the high energy investment needed for economic and social development of the country. Energy demand in Jordan increased largely during the last 20 years and will continue to grow by same rate. The demand of energy is expected to double between 2015-2020 [2]. Energy Audit is defined as "the verification, monitoring and analysis of use of energy including submission of technical report containing recommendations for improving energy efficiency with cost benefit analysis and an action plan to reduce energy consumption". Implementation of recommended measures can help consumers to achieve significant reduction in their energy consumption levels [3]. The audit is designed to determine where, when, why and how energy is being used. This information can then be used to identify opportunities to improve efficiency, decrease energy costs and reduce greenhouse gas emissions that contribute to climate change [4].

Hospitals represent approximately $6 \%$ of total energy consumption in the utility buildings sector. Heating, Ventilation and Air Conditioning (HVAC) systems are the major part of electrical energy consumption at the hospitals. The airconditioning system is responsible for around $70 \%$ of total electricity consumption. Electric motors and lighting systems in a hospital represent approximately $19 \%$ and $21 \%$ of the total energy consumption, respectively. In this paper, profiles of

${ }^{*}$ Corresponding author. Tel.: +96265355000

Fax: +96265355588; E-mail: k.hassouneh@ju.edu.jo

(C) 2017 International Association for Sharing Knowledge and Sustainability

DOI: $10.5383 /$ ijtee.14.01.004 
hospital energy end-use consumption and an overview of energy saving areas at the hospitals are presented [5].

Numerous studies have been made on buildings around the world to reduce its energy consumption and its energy bills. Most studies in this field demonstrate its work on the investigation of electrical systems, lighting system, steam-hot water boilers, cooling system and air conditioning in buildings. Teke et al. [6] made a study of energy savings and efficiency strategies in hospitals, in the study, profiles of hospital energy consumption and an overview of energy saving areas at the hospitals were presented. Hospitals represent approximately $6 \%$ of total energy consumption in the utility buildings sector. Heating, Ventilation and Air Conditioning (HVAC) systems are the major part of electrical energy consumption at the hospitals. The air-conditioning system is responsible for around $70 \%$ of total electricity consumption. Electric motors and lighting systems in a hospital represent approximately $19 \%$ and $21 \%$ of the total energy consumption, respectively.

Ascione et al. [7] carried out energy audit and refurbishment of the Day-Hospital building of a great Italian health care facility. A meticulous energy diagnosis of the base case building and design of a complete renovation- by improving both building envelope and HVAC systems- are presented. Several energy efficiency measures, with reference to building envelope and HVAC systems, are analyzed and it will be evidenced that, stepby-step, a proper design, supported by the adoption of numerical studies, may optimize the energy performances of the building, as well as the indoor microclimatic control. Ali et al [8] conducted a survey in classified hotels in Jordan, to figure out the awareness toward the energy saving behavior in these hotels, he concluded that there is a lack of familiarity among energy saving behaviors, however the hotel stuff showed a high willingness to make change to reduce the power consumptions in their routine working days. Jaber et al. [9] provided a statistics according to the population increase, and how that increase affected the power consumption in the recent years, especially in the commercial sector.

Al-Ghandoor et al. [10] conducted energy audit for an industry running in Jordan; recommendation is illustrated in terms of electrical energy savings, demand savings, cost savings, and payback period. A group of Chinese researchers [11], made a study of building energy audit through a case study about a commercial building in Shanghai. Recorder data of energy consumption of each building service system are used to diagnose the weak points of the building energy-usage system; tap latent power and then a detailed energy audit study were presented.

The aim of this study is to investigate the current level of energy efficiency and then identify cost saving Energy Management solutions and suggest possible methodologies of implementation in the Hospital of the University of Jordan.

The prime objective of the Energy Audit and Assessment is to evaluate the energy consumption of the Hospital in general, prior to attempting to reduce the energy bills by using possible solutions to reduce the consumption of energy, through new technological advancements that could make the running of the hospital smoother and more efficient [12].

\section{Case Study}

The University of Jordan Hospital is located in Amman (32 $\left.0^{\prime} 24.50^{\prime \prime} \mathrm{N}, 35^{\circ} 52^{\prime} 31.62^{\prime \prime} \mathrm{E}\right)$. It is considered one of the largest hospitals in the country. The Hospital receives approximately 34210 patients per year (93 per day). The hospital operates at a capacity of 544beds. The University of Jordan Hospital is one of the leading health care facilities in the region; The work capacity ranges starting from consulting doctors numbering 188; there are 246 residents and 125 specializing doctors, the number of nurses is 860 assisted by 350 managerial employee and 820 aiding assistants; all 2665 employees work as a unit with a high team spirit to assure the delivery of high level of health care to the patients. The main four buildings of the hospital are the Outer Clinics building, the Main building, the Emergencies building and the new Obstetrics and Neonates building, which has been running only in this year of 2013 .

The hospital consumes a monthly average $887,730 \mathrm{kWh}$ of electricity costing 161,566 JD. There are $200-1$ ton of split AC units that are functioning on frequent basis, serving patient, offices and operation rooms - however, there are more units and are used upon need and necessity depending on weather Serving the assisting facilities of the hospital are 7 chillers. The monthly diesel consumption had an average value of 79, 130 Liters costing the amount of (42,769 JDs). Utility costs depending on the energy consumption information of 2012 reaches about 2778426JD.It consists of electricity, diesel, and water. The Hospital spent $(1,938,796 \mathrm{JDs})$ in the year 2012 for the $(10,653$ MWH) electricity consumption along with another (513,231JDs) burning $(949,555$ Liters) of diesel fuel, it is worth mentioning that in the year 2012, the water consumption amounted to $\left(169649 \mathrm{~m}^{3}\right)$ costing $(326,399 \mathrm{JDs})$, resulting in a total cost of $(2,778,426 \mathrm{JDs})$ spent on energy consumption. The electric lighting solutions we attempted brought up a reduction of $(780,580 \mathrm{kWh})$, which makes up $(52 \%)$ of the Lighting bill. Furthermore, regarding the water consumption the savings amount to $\left(22,984 \mathrm{~m}^{3} / \mathrm{yr}\right)$ which amount to $(14 \%)$ of the original amount consumed.

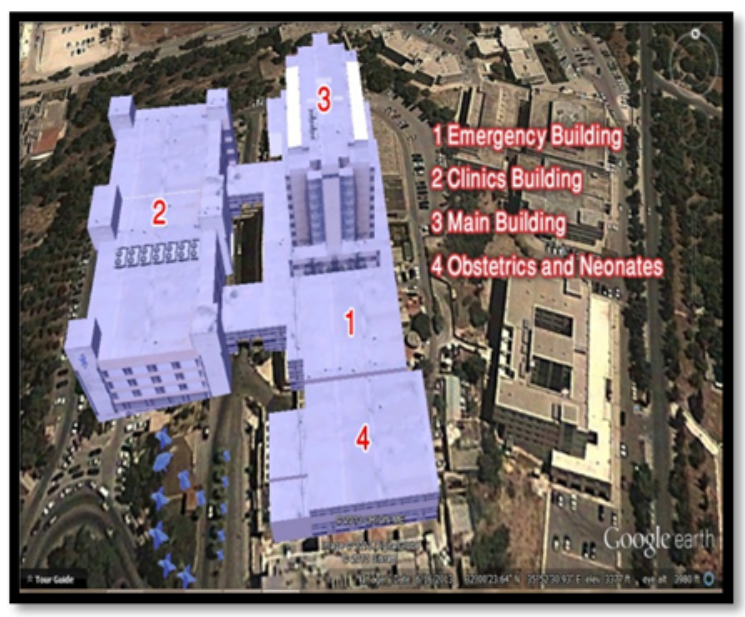

Fig 1: Hospital Layout

The hospital is categorized into 4 zones: Emergency Building $\left(1,393 \mathrm{~m}^{2}\right)$, Out-Patient Clinics Building $\left(3508 \mathrm{~m}^{2}\right)$, Main Building $\left(1404 \mathrm{~m}^{2}\right)$, Obstetrics and Neonates (1786 total Building Area is $8,091 \mathrm{~m}^{2}$ ). Based on the 2012 billing information it is observed that $10,652,760 \mathrm{kWh}$ were consumed, at the cost of $1,938,796$ JDs. It is also observed that 949,555 Liters of diesel were consumed, at the cost of 513,231 JDs and $169,649 \mathrm{~m}^{3}$ of water were consumed at the cost of 326,399 JDs. As shown in the Fig. 2 and Fig. 3, the diesel fuel bills increase significantly in the winter season. On the other hand, the electric bills increase in the summer seasons. For the whole year the electric bill is higher than both the water and fuel bill, this draws 
an initial step to where one may save the highest amount of energy. The two types of HVAC systems used in the hospital are chillers and split units.

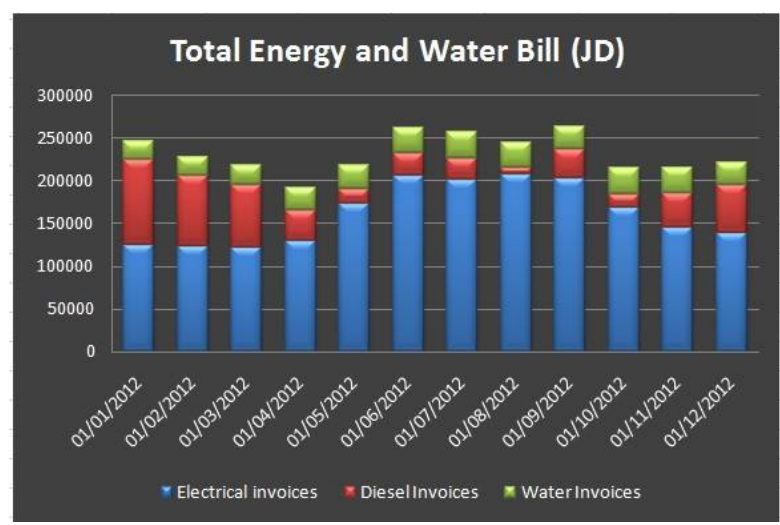

Fig. 2: Monthly Invoices Chart

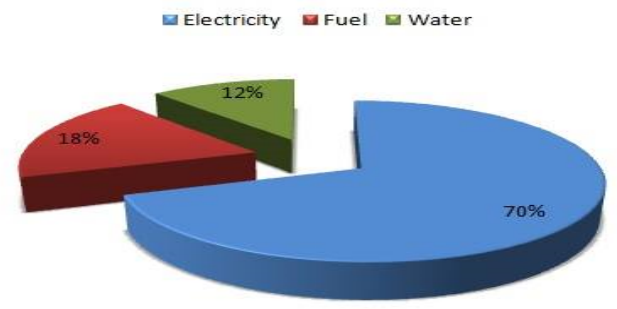

Fig. 3: Total Energy Bill Breakdown

\section{Heating, Ventilation and Air-condition system}

In the University of Jordan Hospital, only one decentralized chiller was accounted for, that had a cooling capacity of 5 tons. There are six centralized chillers serving the hospital. An estimate of 150 split units was counted. All installed units have a capacity of one refrigeration ton. Conditions of units vary from one unit to another, some are functional and some require maintenance. Functionality is also under the discretion of the patient or staffing member. The only maintenance takes place when system shuts down or malfunctions. Therefore, it is recommended that a regular maintenance plan takes place. This is important to keep in check the amount of energy being consumed, as it appears that the amount of energy consumed rises sharply upon a malfunction in any part of the HVAC system. Regular maintenance can be considered as one of the main factor for energy saving. This include thermostats, operation of automatic controls, indoor temperature set points, outdoor air dampers and filter maintenance

\section{Lighting System}

Lighting is an area, which provides a major scope to achieve energy efficiency at the design stage [13].The study has shown that electricity consumed by lighting is the highest ratio among all other categories. The total consumption was $1,501,289 \mathrm{kWh}$ per year costing an amount of 1,938,796JDs. The type of lights used throughout the hospital were, Philips Fluorescent Lights, 60 and $120 \mathrm{~cm}$ rated at $18 \mathrm{~W}$ and $36 \mathrm{~W}$, respectively. There were other types of lights, however infrequently, and were consuming very little electricity to have any measurable effect on the results.
Pathways need to have light access always and energy can be reduced by using proximity sensors.

The solution plan is divided into three parts:

Part 1: Changing the type of light being used instead of using the Fluorescent lamps, it is advised to change to LED lights. For the same lighting output, LED lights offer 60 to $65 \%$ reduction on electricity used (Fluorescent $18 \mathrm{~W}>$ LED $8 \mathrm{~W}-$ Florescent $36>$ LED $18 \mathrm{~W}$ ). LED lights are also superior in the sense that they contain no mercury, LED lights have an extended life time in comparison, which means less lamp replacement and hence lower maintenance cost.

Part 2: Reducing the amount of lights

The number of lights can be reduced, especially in the corridors were the lighting is necessary to see your way through only. This type of solution saves energy without any capital investment. (Taking into considerations that the intensity has a minimum of 50 lux)

Part 3: Scheduled Working Time Intervals:

It is advised at places of infrequent use to use motion sensor as regulators. This will reduce the lights working time, and will therefore save running costs. On the other hand, some parts of the hospital are kept unused for several days, so a control system can be built to turn off the lights as for these days, this will save a considerate value on the lighting bill.

From the previous collected data and analysis many recommendations to reduce the lighting consumption in the hospital, and the values of savings are as follows:

1) Eco - Tube 1200: LED Replacement for the $120 \mathrm{~cm}$ Fluorescent Lamp $(18 \mathrm{~W})^{*}$

2) Eco - Tube 600: LED Replacement for the $120 \mathrm{~cm}$ Fluorescent Lamp $(8 \mathrm{~W})^{*}$

3) Eco - HB - 210W: LED Replacement for the MHD 400

4) Switch: Automatic motion sensor switch

5) Remove 1 from each 5 lamps

Table (1) presents the prices of recommended solutions while Fig. (4) shows the lighting consumption comparison.

Table 1: Prices of recommended solutions

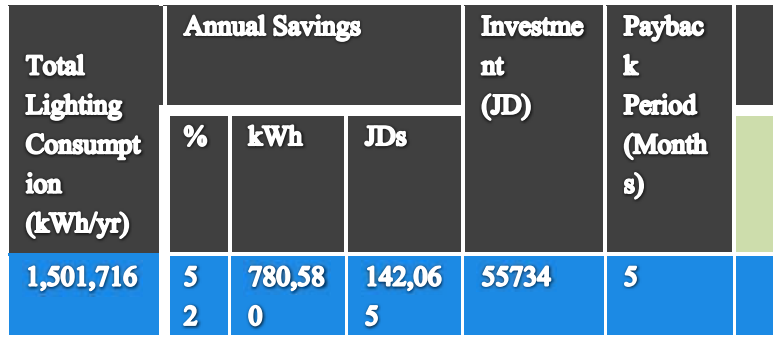




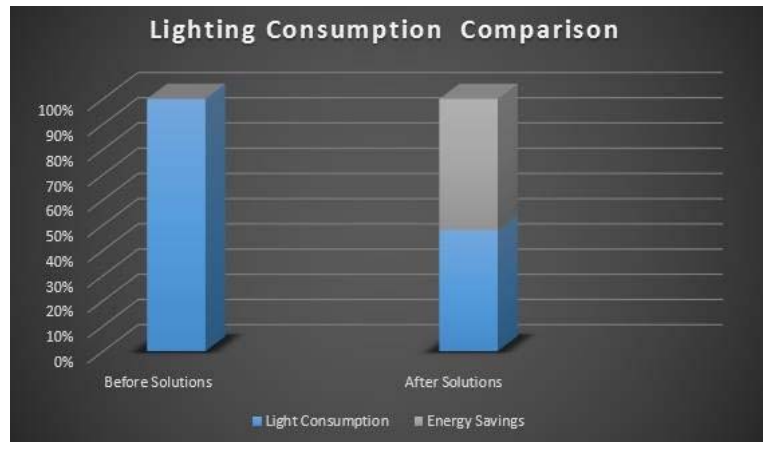

Fig. 4: Lighting consumption comparison

\section{Solar PV System}

As the hospital offers a well exposed, available, and large roof area $\left(6251 \mathrm{~m}^{2}\right)$ photovoltaic installation was a recommended choice. To reduce dependence on diesel fuel; hence, reducing costs and giving the hospital a more lasting solution that can help save money on a longer term. An attempt was made to use the maximum available space on the roofs; the area was split into three main zones. However, certain locations that had weak structure and could not hold the load of the system were excluded; other locations were chillers, compressors, ventilation ducts and space left to extend pipes and to allow for technicians to get through to maintain all system panels, were all excluded too. A distance of 1.5 meters was left from each edge. Each panel was tilted by an angle of 30 degrees; panels were directed towards south. Between each lane of panels and the next, a distance of $1.24 \mathrm{~m}$ was left. The panels were selected from ET SOLAR TM Company, and the panel system we used was Polycrystalline Model. The system is capable of producing 372 $\mathrm{kW}$ peak.

PV System Specifications and Calculations are as follows: The panels selected were of the type ET-P660250BB, with the physical characteristics as shown in the Fig. 5.

\section{PHYSICAL CHARACTERISTICS Unitmm (inch)}
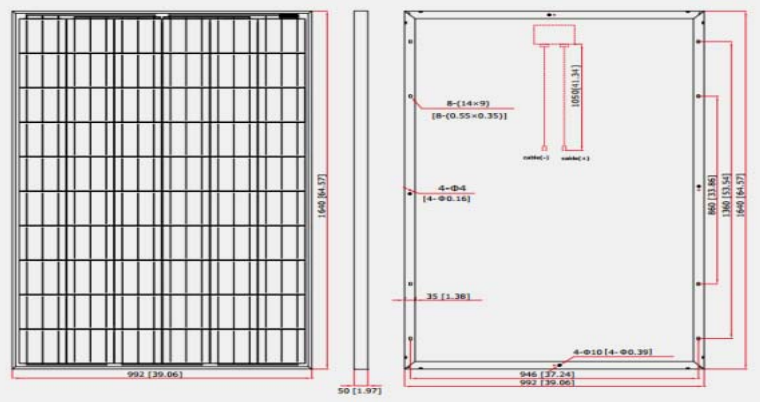

Fig. 5: The Physical Characteristics of the Panel Selected

Using PVSYST ${ }^{\text {тм }}$ Software, the optimum tilt angle for the best annual yield where the optical losses are at minimum value $(0.3$ $\%)$ and the system produces the highest electrical yield, was calculated. The optimum tilt angle calculated for the whole year is $30^{\circ}$ (Fig. 6), where the electric yield are the highest possible, and the optical losses are at minimum percentage. The azimuth angle equals zero for the region of Amman, so the panels will be installed to the south.

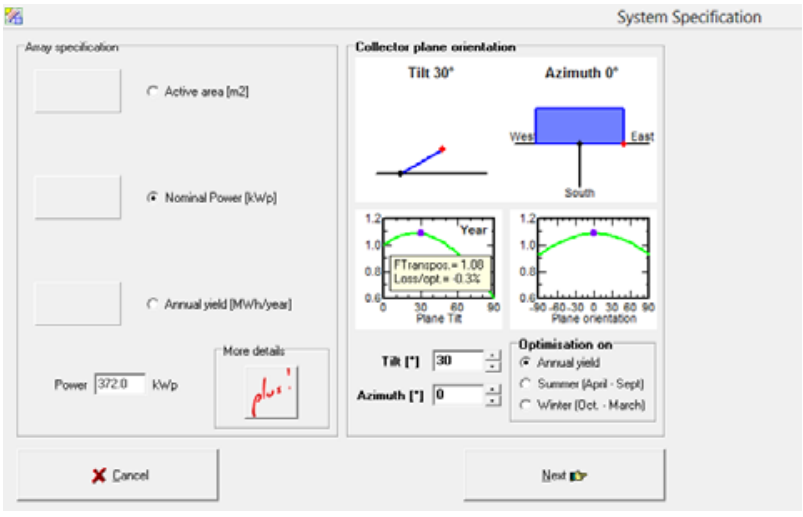

Fig. 6: Optimum angle for the whole year

A sample of PV calculations is shown below Horizontal Projection of each panel:

$$
1.65 * \cos (30)=1.43 \mathrm{~m}
$$

To prevent shading to occur on the modules, we will install the strings with a distance of $1.24 \mathrm{~m}$ this value is calculated as follows.

Distance between strings, so no shading occurs is $=1.5 *$ height

$=1.5 *(1.652-1.432) 0.5=1.24 \mathrm{~m}$

Figure (7) shows the optimum angle for the whole year at the location of the case study in Amman.

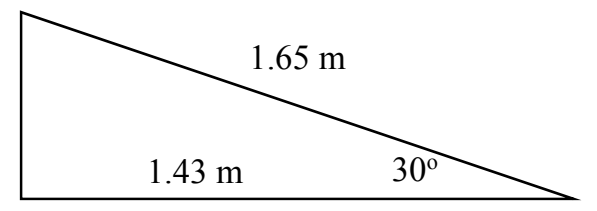

Fig. 7: Optimum angle for the whole year

Following, are the proposed sketches for the designed PV System as shown in Fig. (8).

Zone (1): Emergency Building

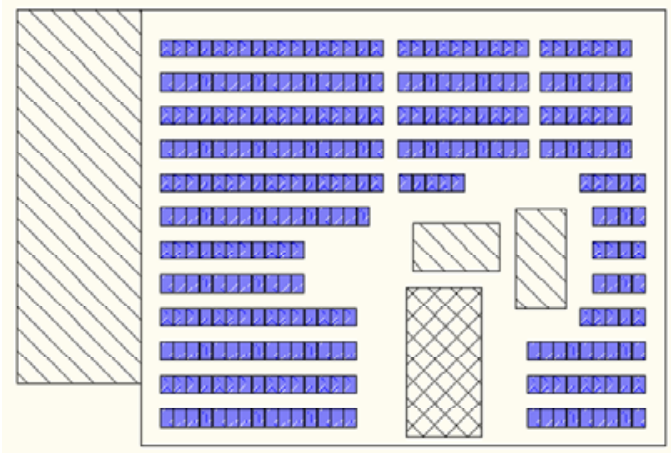

Fig. 8: Zone 1: Emergency Building PV System

Zone (1) Calculations:

No. of Panels $(250 \mathrm{~W} /$ panel $)=366$ Panels

Total Area $=1,339 \mathrm{~m}^{2}$

Payback Period for the PV System Installed = Initial Investment

Annual Energy Delivered $*$ Cost of $1 \mathrm{kWh}$ Electricity

$=520,800 / 152,985$

$=3.4$ years 


\section{Water consumption - study and recommendation}

To show the domestic water consumption numbers in the University of Jordan hospital, the occupancy numbers announced by the hospital have been used as a prime factor in determining the amounts of water. The staff is known to work under three different shifts, morning, evening and a nigh as well. The number of working staff on each shift is 888 employees. The average number of clinical patients visiting the hospital per day, are 1158 patients. Table (2) presented the number of users for domestic hot water while Table (3) shows the domestic water base line.

Table 2: No. of Users for Domestic Hot Water

\begin{tabular}{|l|l|l|}
\hline Area & Numbers & $\begin{array}{l}\text { Full Time } \\
\text { Occupancy }\end{array}$ \\
\hline Hospital Patient & 544 & 1110 \\
\hline Staff & 888 & 2664 \\
\hline Clinic Patient & 1158 & 290 \\
\hline Total & & 4063 \\
\hline
\end{tabular}

Table 3: Domestic Water Base Line

\begin{tabular}{|c|c|c|c|c|c|}
\hline Fixture & 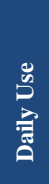 & 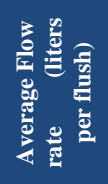 & 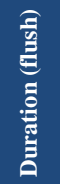 & $\begin{array}{l}\text { है } \\
\text { हैं } \\
\text { हू }\end{array}$ & 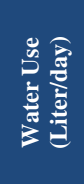 \\
\hline $\begin{array}{l}\text { Water Closet } \\
\text { (2nd flush) }\end{array}$ & 1 & 10 & 1 & 4063 & 40,633 \\
\hline $\begin{array}{l}\text { Water Closet } \\
\text { (1st flush) }\end{array}$ & 1 & 10 & 1 & 4063 & 40,633 \\
\hline Trigger Spray & 2 & 6 & 60 & 4063 & 48,760 \\
\hline Showers & 1 & 10 & 300 & 1110 & 55,488 \\
\hline Faucets & 3 & 10 & 15 & 4063 & 30,475 \\
\hline Total Wat & & on $\mathbf{B}$ & & & 215,990 \\
\hline
\end{tabular}

The University of Jordan Hospital has an occupancy rate of $68 \%$, furthermore, it is known that 544 beds are frequently occupied. An assumption has been made that one fourth of the clinical patients visiting the hospital need and do use water. Figure (9) shows the water breakdown consumption.

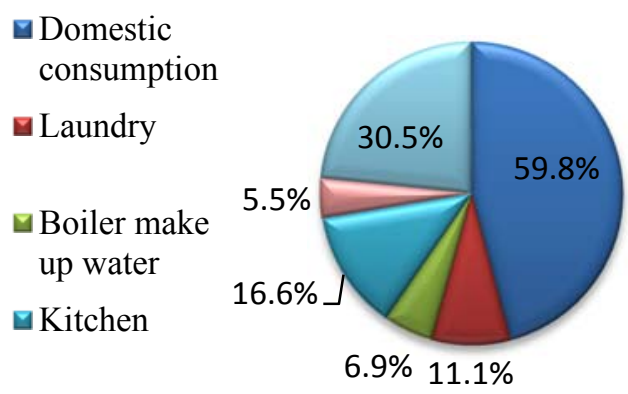

Fig. 9: Water Breakdown Consumptions
After investigation of possible water reduction methods, a feasible and sensible solution was to the install of plastic bottles or containers in the cistern of a higher flush toilet - the device is both cheap and effective in reducing toilet flushes by a daily amount of one or two liters. Another solution is to use bubble aerators for the faucets and showers in the hospital, an aerator saves from $30-50 \%$ of the water flow from the water fixture. Table (4) presented the calculated saving with payback period. Figure (10) shows the water saving from total water usage.

Table 4: Calculated Saving with Payback Period

\begin{tabular}{|l|c|}
\hline Daily Water Saving Liter/Day & 63,844 \\
\hline Daily Water Saving JDs/day & 123 \\
\hline Adjusting Cost (Estimated) & $\mathbf{8 , 7 0 0}$ \\
\hline $\begin{array}{l}\text { Annual Water Saving JDs/Year (Considering } \\
\text { 360 Working Days) }\end{array}$ & 44,220 \\
\hline Estimated Pay Back Period (Months) & 2 \\
\hline Savings Percentage & $30 \%$ \\
\hline $\begin{array}{l}\text { Annual Water Saving } \mathbf{m}^{3} / \text { Year (Considering } \\
\text { 360 Working Days) }\end{array}$ & 22,984 \\
\hline Annual Water consumption $\mathbf{m}^{3} / Y e a r$ & 169,649 \\
\hline Annual Water Saving percentage & $14 \%$ \\
\hline Daily Water consumption m m $^{3 / d a y}$ & 471 \\
\hline
\end{tabular}

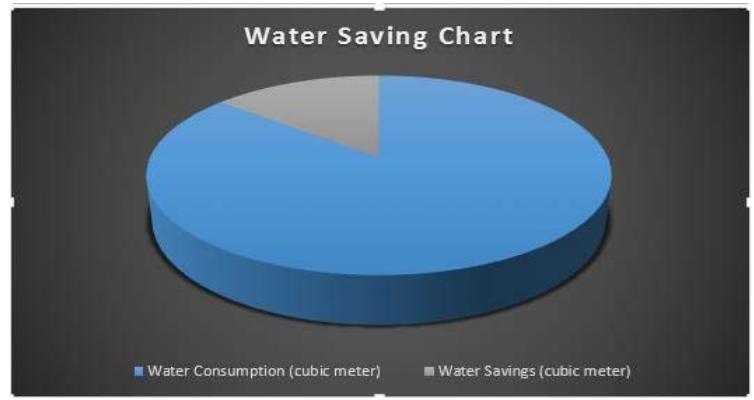

Fig. 10: Water Saving from Total Water Usage

\section{Boiler Management}

A study was carried out to assess the performance of the two hot water boilers, whether for domestic use or heating of spaces. The boilers were installed recently and found to be working on a combustion efficiency of $89.7 \%$. Technician reports that the maintenance carried upon the boilers was quarterly and that so far they have not faced any problems, performance has been consistent ever since [14]. The boiler used was a fire tube type, where the tubes contain flames surrounded by the water to be heated.

Both the boilers are recently installed, and the combustion efficiency is assessed every four months by the company which installed the boilers by using a combustion analyzer., The combustion efficiency of the first boiler was $89.9 \%$ and the total boiler efficiency was $80.3 \%$, the second boiler had an efficiency of $89.7 \%$ and a total efficiency of $80.4 \%$.The boilers were excluded from our solutions in the study, this is due to regular 
inspection by the company which installed the system. These results are summarized in tables (5-7).

Table 5: Installed PV System Summary

\begin{tabular}{|c|c|}
\hline \multicolumn{2}{|c|}{ Photo-Voltaic System Summary } \\
\hline Electric Saving kWh/yr & 651,000 \\
\hline Electric Cost Saving in JD/yr & 152,985 \\
\hline Required Investment ( JD ) & 520,800 \\
\hline Payback Period in Years & 3.4 \\
\hline Percentage of Saving & $8 \%$ \\
\hline
\end{tabular}

Table 6: Lighting Electrical Analysis

\begin{tabular}{|l|l|}
\hline \multicolumn{2}{|c|}{ Electrical Analysis Summary } \\
\hline Electrical Consumption kWh/yr & $10,652,760$ \\
\hline Electrical Cost in JD/yr & $1,938,796$ \\
\hline Electrical Energy Saving kWh/yr & 780,580 \\
\hline Electrical Cost Saving in JD/yr & 142,065 \\
\hline Required Investment ( JD ) & 55,734 \\
\hline Payback Period in Months & 5 \\
\hline Percentage of Saving & $7.3 \%$ \\
\hline
\end{tabular}

Table 7: Water Analysis Summary

\begin{tabular}{|l|l|}
\hline \multicolumn{2}{|c|}{ Water Analysis Summary } \\
\hline Water Consumption $\mathrm{m}^{3} / \mathrm{yr}$ & 169,649 \\
\hline Water Cost in JD/yr & 326,399 \\
\hline Water Saving m $^{3} \mathrm{yr}$ & 22,984 \\
\hline Water Cost Saving in JD/yr & 44,220 \\
\hline Required Investment ( JD ) & 8,700 \\
\hline Payback Period in Months & 2 \\
\hline Percentage of Saving & $14 \%$ \\
\hline
\end{tabular}

\section{Conclusions}

This study aimed to conduct an Energy Auditing of The University of Jordan Hospital. After analyzing electrical issues, this study shows that the hospital can save up to $7.3 \%$ of the energy bill, with a payback period 5 months, the total electrical cost saving is 142,065 Jordan Dinar per year. This saving amount can be achieved by applying saving solutions; changing the type of light being used, reducing the amount of lights and scheduling working time intervals. In order to reduce dependence on diesel fuel, this study suggested installing a photo-voltaic system that offers electric cost saving 152,985 $\mathrm{JD} / \mathrm{yr}$, and $8 \%$ saving percentage of the energy bill. The calculated payback period is 3.4 years. Installing plastic bottles in the cistern of a higher flush toilet and using bubble aerators for the faucets and showers in the hospital can save about 22,984 $\mathrm{m} 3 / \mathrm{yr}$, with a relative water cost saving $44,220 \mathrm{JD} / \mathrm{yr}$, around 14 $\%$ as a saving percentage of the total water bill. The payback period is relatively short, only 2 months, due to the low of the initial cost. The total annual saving will be $339,270 \mathrm{JD} / \mathrm{yr}$, which is $15.0 \%$ of the total water and electricity bill. This leads to the conclusion that energy auditing and simple solutions would be very beneficial to the hospital and to a similar cases in Jordan.

\section{REFERENCES}

[1] Shradha Chandrakant Deshmukh, Varsha Arjun Patil, Energy Conservation and Audit, International Journal of Scientific and Research Publications, Volume 3, Issue 8, August 2013. ISSN 2250-3153, www.ijsrp.org.

[2] K. Hassouneha, A. AlShboula, and A. Al-Salaymehb, Influence of windows on the energy balance of apartment building in Amman, Energy Conversion and Management 51 (2010) 1583-1591

[3] "Auditing transactions" [Online] 2013, Available: http://www.iqmsindia.com.

[4] Harsha.H.U, Nandi, a Case Study Gousia Sultana1, Bangalore, VTU-INDIA,IOSR Journal of Electrical and Electronics Engineering (IOSR-JEEE). E-ISSN: 22781676,p-ISSN: 2320-3331, Volume 10, Issue 3 Ver. III (May - Jun. 2015), PP 01-06 www.iosrjournals.org.

[5] Teke A., Timur O., Overview of Energy Savings and Efficiency Strategies at the Hospitals, World Academy of Science, Engineering and Technology International Journal of Social, Behavioral, Educational, Economic, Business and Industrial Engineering Vol:8, No:1, 2014.

[6] F. Ascione, N. Bianco, R. Francesca De Masi, F. Rossi, C. Stasio and G. Peter Vanoli,Energy Audit of Health Care Facilities: Dynamic Simulation of Energy Performances and Energy-Oriented Refurbishment of System and Equipment for Microclimatic Control,American Journal of Engineering and Applied Sciences 01-2016

[7] Y. Ali, M. Mustafa, Sh. Al-Mashaqbah, Kh. Mashal, M. Mohsen, "Potential of Energy Savings in the Hotel Sector in Jordan", Proceedings of the Third International Conference on Thermal Engineering, May 2007.

[8] J.O. Jaber, M. Mohsen, B. Akash, A.Sarkhi "Energy analysis of Jordan's commercial sector”, ELSEVIER, Feb 2003.

[9] A. Al-Ghandoor. I. Al-Hinti, "Prospects of Energy Savings in the Jordanian Plastic Industry" JJMIE, Dec 2007.

[10] Xin Wang, Chen Huang and Wuwei Cao), "A case study of a commercial building in Shanghai". Sch. of Environ. \& Archit., Univ. of Shanghai for Science \& Technology, Shanghai, China. , (2010

[11] Energy Audit Guide for Buildings, Finish Ministry of Environment, Tallinn, 2001.

[12] Fritz W.L.O and Kahn M.T.E., "Energy Efficient Lighting System"' Journal of Energy, Vol.17 No. 4, November 2006.

[13] Gielen D., Renewable Energy Technologies: Cost Analysis Series, Solar Photovoltaics, Volume 1: Power Sector, Issue 4/5, June 2012

[14] Rahul Dev Gupta, Sudhir Ghai, Ajai Jain. -Energy Efficiency Improvement Strategies for Industrial Boilers: A Case Studyll. Journal of Engineering and Technology. Vol. 1, Issue 1, Jan-June 2011. 